\title{
Article
}

\section{The Impact of Pandemic Management on the Quality of Life of Slovak Dentists}

\author{
Veronika Pacutova 1,2,*, Andrea Madarasova Geckova 1,2,3,4 (D), Peter Kizek 5 , Andrea F. de Winter 4 \\ and Sijmen A. Reijneveld ${ }^{4}$ (D)
}

1 Department of Health Psychology and Research Methodology, Faculty of Medicine, P.J. Safarik University, 04011 Kosice, Slovakia; andrea.geckova@upjs.sk

2 Graduate School Kosice Institute for Society and Health, Faculty of Medicine, P.J. Safarik University in Kosice, 04011 Kosice, Slovakia

3 Olomouc University Social Health Institute, Palacky University, 77515 Olomouc, Czech Republic

4 Department of Community \& Occupational Medicine, University Medical Center Groningen, University of Groningen, 9713 Groningen, The Netherlands; a.f.de.winter@umcg.nl (A.F.d.W.); s.a.reijneveld@umcg.nl (S.A.R.)

5 I. Stomatology Clinic, University Hospital of Louis Pasteur, Faculty of Medicine, P.J. Safarik University, 04011 Kosice, Slovakia; peter.kizek@unlp.sk

* Correspondence: veronika.pacutova@student.upjs.sk

check for updates

Citation: Pacutova, V.; Madarasova Geckova, A.; Kizek, P.; F. de Winter, A.; A. Reijneveld, S. The Impact of Pandemic Management on the Quality of Life of Slovak Dentists. Int J. Environ. Res. Public Health 2021, 18, 5484. https://doi.org/10.3390/ ijerph18105484

Academic Editors: Annina Zysset and Thomas Volken

Received: 18 March 2021

Accepted: 12 May 2021

Published: 20 May 2021

Publisher's Note: MDPI stays neutra with regard to jurisdictional claims in published maps and institutional affiliations.

Copyright: (c) 2021 by the authors. Licensee MDPI, Basel, Switzerland. This article is an open access article distributed under the terms and conditions of the Creative Commons Attribution (CC BY) license (https:// creativecommons.org/licenses/by/ $4.0 /)$.
Abstract: Pandemic management increases the burden on healthcare workers to provide care and also affects their personal lives, with dentists being at particular risk. Therefore, we aim to describe the quality of life (QoL) and limitations experienced due to pandemic management-related measures (PanMan), as well as to assess the association of PanMan with QoL during the first lockdown after the coronavirus outbreak. We obtained data from 500 dentists $(33.2 \%$ males, M/SD $=43.8$ ) registered with the Slovak Chamber of Dentists using an online questionnaire. We categorized PanMan as the availability of personal protective equipment (PPE) and the ability to implement anti-pandemic measures, information overload, pandemic-related limitations and QoL in terms of their impact on family life and activities, housekeeping, relationships with relatives, financial situation and mental well-being. PanMan mainly affected financial situation, mental well-being and housekeeping. Factors contributing most towards the worsening of QoL were information overload (odds ratio/95\% confidence interval, OR/CI: 5.79/2.64-12.71) and several pandemic-related limitations. These consisted of (OR/CI): a lack of PPE (5.17/2.48-10.77), infection risks in the work environment (3.06/1.57-5.95), obligatory safety measures (3.02/1.47-6.21), lack of staff (2.85/1.30-6.25) and client concerns (3.56/1.70-7.49). Pandemic management has led to a considerable worsening of dentists' QoL.

Keywords: COVID-19; pandemic management; quality of life; dentists; healthcare workers

\section{Introduction}

Coronavirus disease (COVID-19) and management of this pandemic had unprecedented consequences on the quality of life of healthcare workers (HCWs). Globally, COVID19 has taken 2,659,802 lives as of 18 March 2021 [1], and in the first wave of the disease, before the possibility of being vaccinated, only pandemic management-related measures were in force to save human lives. Similar to other countries, Slovakia began to introduce early pandemic management (such as temperature screening, deep sanitation, closing schools and cancelling organized events) from the end of February 2020, and continued by enforcing the wearing of face masks, the closing of non-essential stores, a mandatory 14-day quarantine and home isolation. On 15 March 2020, Slovakia declared an "emergency healthcare situation" to provide the possibility of transferring healthcare workers from one hospital to another with no option of refusing to provide healthcare or declaring a strike [2]. 
However, pandemic management had already changed and affected the quality of life in physical, mental and social domains, both positively and negatively [3].

Healthcare workers were particularly vulnerable to the pandemic, but also to the side-effects of pandemic management-related measures. They stand on the frontline of a high-risk infectious work environment. Society also stigmatized HCWs and their relatives, with many members of the public avoiding them based on the belief that they could be a source of infection because of their profession and their contact with patients [4].

Dentists are a group of healthcare workers who had to drastically change their way of providing care during this outbreak. They typically have close contact with a patient's mucosa, which could potentially be an easy way of virus transmission $[5,6]$. Pandemic management focused on dental care aimed to minimize the risk of infection by limiting the number of treatments, excluding preventive check-ups and dental hygiene from services and allowing only "emergency cases" to be provided, with permitted hours from 8:00 a.m. until 12:00 p.m. Dentists were supposed to secure and wear personal protective equipment (FFP3/N95; closed glasses or full face shield; covering for the head, hands and legs; disposable gloves; shoe covers), and to maintain frequent disinfection with a reduced numbers of coworkers [7]. Both the pandemic and pandemic management-related measures are thus likely to have affected various aspects of the work and private lives of dentists, but evidence on this is fully lacking. Therefore, we aim to describe the quality of life (QoL) and limitations dentists experienced due to pandemic management-related measures (PanMan), as well as to assess the association of PanMan with QoL during the first lockdown after the coronavirus outbreak.

\section{Materials and Methods}

\subsection{Sample}

The study investigated all practicing dentists working in Slovakia $(n=3884)$, who were members of the Slovak Chamber of Dentists. These dentists were invited to participate in an online questionnaire from 8-12 October 2020; the invitation was sent by the administration of the Chamber to protect the privacy of the registered dentists. The questionnaire was specifically developed in cooperation with experts from the target population (Supplementary File). During multiple consultations with them, we elicited the relevant issue, drafted the questions, adjusted them based on their comments and piloted a draft final version to assure the clarity and appropriateness of the questionnaire. We received 635 responses, of which 15 participants had not filled in any of the questions. From those who filled in the questionnaire, we excluded those who did not report sex $(n=113)$ and those who were not dentists ( 2 nurses, 5 others); thus, the final sample consisted of 500 respondents ( $n=166$, $33.2 \%$ males, mean age $/ \mathrm{SD}=43.8 / 14.4$ ).

\subsection{Measures and Procedures}

\subsubsection{Impact on the Quality of Life (QoL)}

The impact on various fields of QoL was measured by asking respondents if difficulties in providing healthcare due to the introducing of pandemic management affected their (a) family life and activities, (b) housekeeping, (c) relationships with relatives, (d) financial situation and (e) mental well-being during the first wave of the COVID-19 pandemic. Answers on a Likert scale were dichotomized into those reporting worsening (slightly/significantly worsened) and improving (slightly/significantly improved vs. did not change) effects in a particular area of life.

\subsubsection{Impact of Pandemic Management-Related Measures (PanMan)}

We measured PanMan as the availability of PPE and the ability to implement antipandemic measures, information overload and pandemic-related limitations. The availability of PPE covered whether respondents had all the necessary PPE at their disposal (personal contact with clients was excluded; were able/unable to fully assure protection; had to sometimes work in insufficiently protected conditions). The ability to implement 
anti-pandemic measures investigated how well respondents were able to implement and maintain anti-pandemic measures (unable/able to fully implement vs. unable to implement at all) during the first lockdown (March-June 2020). The following three groups of respondents were differentiated: not enough PPE and/or were unable to implement vs. enough PPE and able to implement fully protective measures. Information overload covered how frequently respondents followed news about the pandemic during the first lockdown (March-June 2020), and how much they were concerned about pandemic news. Combining these two questions, we divided the respondents into those who did not follow the news and / or were not concerned vs. those who followed the news several times per day and/or were highly concerned. Pandemic-related limitations of healthcare provision investigated (a) a lack of PPE, (b) infection risks in the work environment, (c) obligatory safety measures, (d) a lack of staff and (e) client concerns. Respondents were asked how much they were hindered in providing healthcare in its original quality during the first lockdown (March-June 2020). Answers on a Likert scale were dichotomized as partially/not limited vs. limited/significantly limited for each subcategory.

\subsubsection{Background Characteristics}

We further measured the following background characteristics: gender, age and work position.

\subsection{Statistical Analysis}

First, we described the background characteristics of the sample using descriptive statistics. Second, we described the QoL of dentists and the limitations experienced due to exposure to pandemic management-related measures, using prevalence data. Finally, we assessed the associations of PanMan (the availability of PPE and the ability to implement anti-pandemic measures, information overload, and pandemic-related limitations of the healthcare provided) with quality of life (family life and activities, housekeeping, relationships with relatives, financial situation, mental well-being) as separate outcomes, using logistic regression models with adjustment for gender and age. We used IBM SPSS Statistics 23 for Windows for preparing all analyses.

\section{Results}

\subsection{Background Characteristics}

The majority of dentists in our sample were owners of private dental clinics $(77.8 \%$ of participants; $n=389)$, while $28.2 \%(n=141)$ worked at private clinics and only $2.0 \%$ $(n=10)$ were from state dental clinics. Most of them were traditional dentists $(86.2 \%$ of participants; $n=431)$ who treated adult and child clients $(n=467 ; 93.4 \%$; Table 1$)$.

Table 1. Demographic characteristics of the respondents (Slovakia 2020; $n=500$ dentists).

\begin{tabular}{ll}
\hline Variables & $\boldsymbol{n} \mathbf{( \% )}$ \\
\hline Sex: & \\
Women & $334(66.8)$ \\
Men & $166(33.2)$ \\
Type of dental clinic: & $389(77.8)$ \\
Private dental clinics-owners & $141(28.2)$ \\
Private dental clinics-employees & $10(2.0)$ \\
State dental clinics & \\
Specialization of dentists: & $431(86.2)$ \\
Traditional dentists & $58(11.6)$ \\
Specialized dentists & $11(2.2)$ \\
Other & \\
Type of patients treated: & $467(93.4)$ \\
Adults and children & $24(4.8)$ \\
Only adults & $9(1.8)$ \\
Only children &
\end{tabular}




\subsection{Impact on Quality of Life and Exposure to PanMan}

Most dentists reported that the pandemic has had an impact on their QoL, mostly regarding their financial situation and their mental well-being (85 and $70 \%$ of participants, respectively). The most frequently reported problems were those related to infection risks in their work environment and lack of PPE, reported by 63 and $55 \%$ of respondents respectively (Table 2).

Table 2. Impact on quality of life (QoL) and exposure to effects of the pandemic management (PanMan) (Slovakia 2020; $n=500$ dentists).

\begin{tabular}{ll}
\hline Variables & $\boldsymbol{n} \mathbf{( \% )}$ \\
\hline Slightly/Significantly worsened QoL in: & $190(45.0)$ \\
Family life and activities & $149(35.4)$ \\
Housekeeping & $89(21.1)$ \\
Relationships with relatives & $362(85.4)$ \\
Financial situation & $298(70.3)$ \\
Mental well-being & $222(48.7)$ \\
PanMan: & $93(19.6)$ \\
Availability of PPE and ability to implement anti-pandemic measures ${ }^{1}$ & $200(54.9)$ \\
Information overload $^{2}$ & $219(62.6)$ \\
Pandemic-related limitation due to lack of PPE ${ }^{3}$ & $169(49.6)$ \\
Pandemic-related limitation due to infection risks in the work environment ${ }^{3}$ & $131(38.8)$ \\
Pandemic-related limitation due to obligatory safety measures ${ }^{3}$ & $164(47.1)$ \\
Pandemic-related limitation due to lack of staff $^{3}$ & \\
Pandemic-related limitation due to client concerns $^{3}$ & \\
\hline
\end{tabular}

${ }^{1}$ Not enough personal protective equipment (PPE) and unable to implement anti-pandemic measures; ${ }^{2}$ followed the news several times per day and was highly concerned; ${ }^{3}$ limited/significantly limited.

\subsection{Association of PanMan with QoL}

Regarding QoL-family life, dentists who followed pandemic news several times per day and were concerned were more likely to report worsening effects on family life and activities (odds ratio/95\% confidence interval, OR/CI: 1.71/1.02-2.88) than dentists who did not follow pandemic news. Findings are displayed in Table 3.

Regarding QoL-housekeeping, dentists who did not have enough PPE and were unable to implement anti-pandemic measures were more likely to report worsening effects on housekeeping (OR/CI: 1.88/1.11-3.20) than those whose had enough PPE and were able to implement anti-pandemic measures. Additionally, dentists who followed pandemic news several times per day and were concerned more frequently reported worsening effects on housekeeping (OR/CI: 2.58/1.51-4.40) than dentists who did not follow pandemic news. Moreover, those who reported that the care provided was limited/significantly limited due to a lack of PPE (OR/CI: 1.70/1.09-2.67), obligatory safety measures (OR/CI: 1.94/1.22-3.07) and a lack of staff (OR/CI: 1.89/1.18-3.01) were more likely to have felt worsening effects on housekeeping than those dentists who were partially/not limited.

Regarding QoL-relationships with relatives, dentists who reported that the care provided was limited/significantly limited due to a lack of staff (OR/CI: 2.78 (1.63-4.77) and client concerns (OR/CI: 2.09/1.23-3.54), were more likely to have felt worsening effects on their relationships with relatives than those dentists who were partially/not limited in their care. 
Table 3. The association of pandemic management with the quality of life of dentists; results of logistic regression analyses adjusted for age and gender leading to odds ratios, OR, and 95\% confidence intervals (95\%CI).

\begin{tabular}{|c|c|c|c|c|c|}
\hline Variables & $\begin{array}{l}\text { Family Life } \\
\text { and Activities } \\
\text { OR }(95 \% C I)\end{array}$ & $\begin{array}{l}\text { Housekeeping } \\
\text { OR }(95 \% \text { CI })\end{array}$ & $\begin{array}{l}\text { Relationships } \\
\text { with Relatives } \\
\text { OR }(95 \% \text { CI })\end{array}$ & $\begin{array}{l}\text { Financial } \\
\text { Situation } \\
\text { OR }(95 \% C I)\end{array}$ & $\begin{array}{l}\text { Mental } \\
\text { Well-Being } \\
\text { OR (95\%CI) }\end{array}$ \\
\hline \multicolumn{6}{|c|}{ Availability of PPE and ability to implement anti-pandemic measures } \\
\hline $\begin{array}{l}\text { Enough PPE and able to } \\
\text { implement }\end{array}$ & Ref & Ref & Ref & Ref & Ref \\
\hline $\begin{array}{l}\text { Not enough PPE or unable to } \\
\text { implement }\end{array}$ & $1.28(0.74-2.23)^{\mathrm{ns}}$ & $1.13(0.62-2.06)^{\text {ns }}$ & $1.12(0.55-2.31)^{\mathrm{ns}}$ & $2.41(1.16-5.01) *$ & $1.06(0.60-1.87)^{\mathrm{ns}}$ \\
\hline $\begin{array}{l}\text { Not enough PPE and unable to } \\
\text { implement }\end{array}$ & $1.46(0.89-2.40)^{\mathrm{ns}}$ & $1.88(1.11-3.20) *$ & $1.73(0.92-3.24)^{n s}$ & $2.72(1.41-5.24) * *$ & $2.15(1.26-3.68) * *$ \\
\hline Age (in years) & $1.01(1.00-1.03)^{\mathrm{ns}}$ & $1.02(1.00-1.03) *$ & $1.01(1.00-1.03)^{\mathrm{ns}}$ & $1.03(1.01-1.06) * *$ & $1.01(1.00-1.03)^{\mathrm{ns}}$ \\
\hline Male (vs. female) & $1.05(0.70-1.60)^{n s}$ & $0.81(0.52-1.26)^{n s}$ & $0.88(0.53-1.47)^{n s}$ & $0.87(0.49-1.57)^{n s}$ & $0.67(0.43-1.04)^{n s}$ \\
\hline \multicolumn{6}{|l|}{ Information overload } \\
\hline $\begin{array}{l}\text { Did not follow, was not } \\
\text { concerned }\end{array}$ & Ref & Ref & Ref & Ref & Ref \\
\hline $\begin{array}{l}\text { Followed the news or highly } \\
\text { concerned }\end{array}$ & $1.36(0.87-2.13)^{\mathrm{ns}}$ & $1.37(0.85-2.20)^{\mathrm{ns}}$ & $1.66(0.97-2.85)^{\mathrm{ns}}$ & $0.96(0.52-1.75)^{\mathrm{ns}}$ & $1.55(0.96-2.50)^{n s}$ \\
\hline $\begin{array}{l}\text { Followed the news and highly } \\
\text { concerned }\end{array}$ & $1.71(1.02-2.88)$ * & $2.58(1.51-4.40) * * *$ & $1.32(0.70-2.49)^{\mathrm{ns}}$ & $2.78(1.04-7.46) *$ & $5.79(2.64-12.71) * * *$ \\
\hline Age (in years) & $1.01(1.00-1.02)^{\mathrm{ns}}$ & $1.01(1.00-1.02)^{\mathrm{ns}}$ & $1.01(1.00-1.03)^{\mathrm{ns}}$ & $1.02(1.00-1.04) *$ & $1.00(0.99-1.02)^{\mathrm{ns}}$ \\
\hline Male (vs. female) & $1.09(0.72-1.65)^{n s}$ & $0.84(0.54-1.31)^{n s}$ & $0.90(0.53-1.49)^{\mathrm{ns}}$ & $0.84(0.47-1.50)^{n s}$ & $0.71(0.45-1.11)^{n s}$ \\
\hline \multicolumn{6}{|c|}{$\begin{array}{l}\text { Providing healthcare limited due to: } \\
\text { Lack of PPE }\end{array}$} \\
\hline Partially limited/ not limited & Ref & Ref & Ref & Ref & Ref \\
\hline Limited/ Significantly limited & $1.27(0.83-1.94)^{\mathrm{ns}}$ & $1.70(1.09-2.67) *$ & $1.73(1.02-2.92)^{\mathrm{ns}}$ & $5.17(2.48-10.77) * * *$ & $1.71(1.07-2.73) *$ \\
\hline Age (in years) & $1.01(0.99-1.02)^{n s}$ & $1.02(1.00-1.03) *$ & $1.01(1.00-1.03)^{n s}$ & $1.03(1.01-1.06) * *$ & $1.02(1.00-1.03)^{n s}$ \\
\hline Male (vs. female) & $1.22(0.78-1.90)^{n s}$ & $0.90(0.56-1.44)^{\mathrm{ns}}$ & $1.11(0.65-1.91)^{n s}$ & $1.19(0.59-2.39)^{\mathrm{ns}}$ & $0.76(0.47-1.24)^{\mathrm{ns}}$ \\
\hline \multicolumn{6}{|l|}{$\begin{array}{l}\text { Infection risks in the work } \\
\text { environment }\end{array}$} \\
\hline Partially limited/ not limited & Ref & Ref & Ref & Ref & Ref \\
\hline Limited/ Significantly limited & $1.07(0.69-1.66)^{\mathrm{ns}}$ & $1.42(0.89-2.27)^{n s}$ & $1.33(0.78-2.28)^{n s}$ & $3.06(1.57-5.95) * * *$ & $1.86(1.15-3.01) *$ \\
\hline Age (in years) & $1.01(0.99-1.02)^{\mathrm{ns}}$ & $1.02(1.00-1.03)$ * & $1.01(1.00-1.03)^{n s}$ & $1.03(1.00-1.06) *$ & $1.01(1.00-1.03)^{n s}$ \\
\hline Male (vs. female) & $1.23(0.78-1.94)^{n s}$ & $0.91(0.57-1.48)^{n s}$ & $1.01(0.58-1.73)^{n s}$ & $1.07(0.53-2.17)^{\mathrm{ns}}$ & $0.76(0.46-1.25)^{n s}$ \\
\hline \multicolumn{6}{|l|}{ Obligatory safety measures } \\
\hline Partially limited/ not limited & Ref & Ref & Ref & Ref & Ref \\
\hline Limited/ Significantly limited & $1.00(0.65-1.55)^{\mathrm{ns}}$ & $1.94(1.22-3.07) * *$ & $1.66(0.97-2.84)^{n s}$ & $3.02(1.47-6.21) * *$ & $1.94(1.18-3.18) * *$ \\
\hline Age (in years) & $1.01(0.99-1.02)^{n s}$ & $1.01(1.00-1.03)^{\mathrm{ns}}$ & $1.01(0.99-1.03)^{n s}$ & $1.03(1.00-1.05) *$ & $1.01(0.99-1.03)^{\mathrm{ns}}$ \\
\hline Male (vs. female) & $1.18(0.74-1.88)^{n s}$ & $0.96(0.58-1.57)^{n s}$ & $1.12(0.64-1.98)^{n s}$ & $1.21(0.60-2.45)^{\mathrm{ns}}$ & $0.82(0.49-1.36)^{n s}$ \\
\hline \multicolumn{6}{|l|}{ Lack of staff } \\
\hline Partially limited/ not limited & Ref & Ref & Ref & Ref & Ref \\
\hline Limited/ Significantly limited & $1.14(0.73-1.78)^{n s}$ & $1.89(1.18-3.01) * *$ & $\begin{array}{l}2.78(1.63-4.77) \\
* * *\end{array}$ & $2.85(1.30-6.25) * *$ & $2.41(1.40-4.16) * *$ \\
\hline Age (in years) & $1.01(0.99-1.02)^{\mathrm{ns}}$ & $1.02(1.00-1.03) *$ & $1.01(1.00-1.03)^{\mathrm{ns}}$ & $1.03(1.01-1.06) *$ & $1.01(1.00-1.03)^{\mathrm{ns}}$ \\
\hline Male (vs. female) & $1.21(0.76-1.93)^{n s}$ & $0.91(0.56-1.49)^{n s}$ & $1.19(0.67-2.10)^{n s}$ & $1.04(0.51-2.11)^{\mathrm{ns}}$ & $0.72(0.43-1.20)^{n s}$ \\
\hline \multicolumn{6}{|l|}{ Client concerns } \\
\hline Partially limited/ not limited & Ref & Ref & Ref & Ref & Ref \\
\hline Limited/ Significantly limited & $0.99(0.64-1.52)^{\mathrm{ns}}$ & $1.30(0.83-2.04)^{n s}$ & $2.09(1.23-3.54) * *$ & $3.56(1.70-7.49) * * *$ & $2.06(1.26-3.38) * *$ \\
\hline Age (in years) & $1.01(0.99-1.02)^{n s}$ & $1.02(1.00-1.03)^{n s}$ & $1.01(1.00-1.03)^{\mathrm{ns}}$ & $1.04(1.01-1.07) * *$ & $1.02(1.00-1.03)^{\mathrm{ns}}$ \\
\hline Male (vs. female) & $1.19(0.75-1.87)^{\mathrm{ns}}$ & $0.84(0.52-1.36)^{n s}$ & $1.03(0.59-1.79)^{\mathrm{ns}}$ & $0.97(0.48-1.97)^{\mathrm{ns}}$ & $0.70(0.43-1.16)^{n s}$ \\
\hline
\end{tabular}

${ }^{*} p<0.05 ;{ }^{* *} p<0.01 ;{ }^{* * *} p<0.001 ;{ }^{\text {ns }}$ - non significant; significant values in bold; Ref - reference value

Regarding QoL-financial situation, dentists who did not have enough PPE or/and were unable to implement anti-pandemic measures were more likely to report worsening effects on their financial situation (OR/CI: 2.41/1.16-5.01; OR/CI: 2.72/1.41-5.24) than those whose had enough PPE and were able to implement anti-pandemic measures. In addition, dentists who followed pandemic news several times per day and were concerned were more likely to report worsening effects on their financial situation (OR/CI: 2.78/1.04-7.46) than dentists who did not follow pandemic news. Moreover, those who 
reported that the care provided was limited/significantly limited due to a lack of PPE (OR/CI: 5.17/2.48-10.77), infection risks in the work environment (OR/CI: 3.06/1.57-5.95), obligatory safety measures (OR/CI: 3.02/1.47-6.21), a lack of staff (OR/CI: 2.85/1.30-6.25) and client concerns (OR/CI: 3.56/1.70-7.49), were more likely to feel worsening effects on their financial situation than those dentists who were partially/not limited.

Regarding QoL-mental well-being, dentists who did not have enough PPE and were unable to implement anti-pandemic measures were more likely to report worsening effects on their mental well-being (OR/CI: 2.15/1.26-3.68) than those who had enough PPE and were able to implement anti-pandemic measures. In addition, dentists who followed pandemic news several times per day and were concerned were more likely to report worsening effects on mental well-being (OR/CI: 5.79/2.64-12.71) than dentists who did not follow pandemic news. Moreover, those who reported that the care provided was limited/significantly limited due to a lack of PPE (OR/CI: 1.71/1.07-2.73) and reported infection risks in the work environment (OR/CI: 1.86/1.15-3.01), obligatory safety measures (OR/CI: $1.94 / 1.18-3.18)$, a lack of staff (2.41/1.40-4.16) and client concerns (OR/CI: 2.06/1.26-3.38) were more likely to feel worsening effects on mental well-being than those dentists who were partially/not limited.

\section{Discussion}

Dentists reported a poorer quality of life due to pandemic management-related measures aiming to prevent the spread of COVID-19 applied during lockdown, with more than $70 \%$ of them reporting worsening effects on both their financial situation and their mental health. In particular, some PanMan-related measures were felt to have been limiting, e.g., infection risks in work environment and a lack of PPE. PanMan in particular affected their financial situation, mental well-being and housekeeping.

We found the worst effects on QoL ( $85 \%$ ) to be concerning financial situation, with the strongest associations concerning a lack of PPE and client concerns. The dentists' financial situation was impacted most by the pandemic management-related measures that limited the number of treatments allowed [5]. Our data show that the number of patients dentists treated daily during lockdown dropped from 15-20 to less than 5. In addition, those who wanted to protect their family and not risk infection at work closed their clinics with financial concerns. Furthermore, on top of the reduced income, their expenditures increased due to mandatory personal protective equipment for healthcare workers, which were also highly overpriced at the beginning of the pandemic [6]. Dentists could not afford to stay unprotected and desperately needed to ensure PPE so that they would have the opportunity to provide safe care. Unfortunately, in some cases they were forced to reuse PPE, or work with badly fitting or no PPE [8-10]. Evidently, this impact on their finances also affected their mental well-being [11].

Mental well-being was the second most-severely affected domain of QoL, with the strongest associations concerning information overload and a lack of staff. All financial concerns, as well as limitations related to housekeeping, could affect the mental well-being of dentists, in whom a 70\% increase in worsening effects was reported. COVID-19 and pandemic management measures could act as a stressor in their lives, and cause anxiety or depression [6,12-14]. Moreover, the required wearing of prescribed personal protective equipment led to discomfort and the development of skin problems, for example [15]. Other accompanying phenomena were panic, fear, exhaustion, anger, stigmatization or confusion $[4,13]$. This combination, along with the increased workload, also had the potential to lead to burnout or post-traumatic stress disorder [13,14,16-20], i.e., greatly affecting mental well-being. In other studies about healthcare workers' QoL, the focus was mainly on nurses or physicians and their mental health. Burnout or secondary traumatization was associated with depression and anxiety, which caused an overall lower QoL [21-24]. Studies focusing on other healthcare professions, e.g., physiotherapists and optometrists, are still unpublished. 
We found that $35 \%$ of all dentists reported a worsening of QoL, particularly in the field of housekeeping. The reason could be that a lack of proper information about the COVID-19 virus at the beginning of the pandemic coupled with the frequently changing pandemic management could have led to confusion and complication in the process of ensuring basic household supplements [25], household management and providing childcare. The increased workload of HCWs in general may have led to a decrease in time available for housekeeping [9], whereas this requires more time in general because of necessary cooking at home and coping with the possibility of closed stores. Furthermore, dentists who were parents had to take full responsibility for childcare and home-schooling, due to school closures and disappearing "helping hands" from grandparents, something which was required in order to protect the health of the elderly [26]. Gender differences may have contributed further, as most respondents were female and may have been taking care of the household and children more often [26,27].

PanMan had relatively less impact on QoL in the fields of family life and activities, as well as in relationships with relatives. An explanation may be that these relationships were relatively good, with the literature showing that even one strong supportive relationship could be enough to balance the impact of the pandemic [28]. Another explanation could be the wording of the question concerned, i.e., that respondents did not attribute worsened QoL to their ability to provide care. Evidently, this requires further study.

\subsection{Strengths and Limitations}

The main strength of our study is that we obtained a rather large national sample of dentists during the first wave of the COVID-19 pandemic. Moreover, we were able to gather information about the impact of a number of measures on a rather wide range of relevant QoL domains. However, some limitations should be considered. The major limitation may be the fact that the study is a picture of the situation during the first lockdown dentists ever encountered and is based on voluntary participation in an online survey. Results may thus have been affected by insufficient technological ability to complete the survey and could be different in the following waves of the COVID-19 outbreaks. Second, the online invitation for the survey via the Slovak Chamber of Dentists resulted in a relatively low response rate $(12.9 \%)$, but the age and gender composition of our sample was quite similar to the target population, i.e., dentists registered in the Slovak Chamber of Dentists. There were slightly more female responses in our sample than the target population $(66.8 \% \mathrm{vs}$. $61.4 \%)$, and fewer dentists over 66 years old (10.0\% vs. $20.1 \%)$, the latter group being extremely small. Because of the adjustments we made for age and gender, this was unlikely to affect the findings. Third, the validity of the questions as they were asked deserves further confirmation.

\subsection{Implications}

Our findings on the first pandemic situation in Slovakia show the importance of proper crisis management and anti-pandemic measures to ensure a safe work environment for dentists. The impact of anti-pandemic measures should continue to be assessed. Measures such as closing schools and kindergartens, stopping leisure activities for children and limitations in providing services create a large additional burden for families, in terms of managing their household and parenting. These measures should be balanced against their added value in curtailing the pandemic. Part of crisis management should be the provision of psychological support or peer support to dentists and their families, and similarly to other HCWs, support by governmental authorities. Dentists should not be forgotten amongst the pandemic essential care workers when mental support is to be offered. These findings require confirmation from other countries with other types of anti-pandemic measures. 


\section{Conclusions}

Pandemic management has led to a considerable worsening of dentists' QoL, in particular because of information overload and several pandemic-related limitations, i.e., a lack of PPE, infection risks in the work environment, obligatory safety measures, a lack of staff and client concerns.

Supplementary Materials: The following are available online at https://www.mdpi.com/article/10 .3390/ijerph18105484/s1.

Author Contributions: Conceptualization: V.P., A.M.G., P.K., A.F.d.W. and S.A.R. Validation: V.P., A.M.G., P.K., A.F.d.W. and S.A.R. Data curation: V.P., A.M.G., P.K., A.F.d.W. and S.A.R. Formal analysis: V.P., A.M.G., P.K., A.F.d.W. and S.A.R. Methodology: V.P., A.M.G., P.K., A.F.d.W. and S.A.R. Writing—original draft: V.P., A.M.G., P.K., A.F.d.W. and S.A.R. Writing—review and editing: V.P., A.M.G., P.K., A.F.d.W. and S.A.R. All authors have read and agreed to the published version of the manuscript.

Funding: This work was supported by the Research and Development Support Agency under Contract No. VVGS-2020-1444, APVV-16-0490.

Institutional Review Board Statement: The study was conducted according to the guidelines of the Declaration of Helsinki, and approved by the Ethics Committee of the Faculty of Medicine at P. J. Safarik University $(14 \mathrm{~N} / 2020)$.

Informed Consent Statement: Informed consent was obtained from all subjects involved in the study.

Data Availability Statement: The data presented in this study are available on request from the corresponding author.

Conflicts of Interest: The authors declare no conflict of interest.

\section{References}

1. European Centre for Disease Prevention and Control. Available online: https://www.ecdc.europa.eu/en/geographicaldistribution-2019-ncov-cases (accessed on 18 March 2021).

2. Office of Public Health of Slovak Republic. Available online: https://www.uvzsr.sk/index.php?option=com_content\&view= frontpage\&Itemid $=1$ (accessed on 25 February 2021).

3. Centers for Disease Control and Prevention. Available online: https:/ /www.cdc.gov/hrqol/concept.htm (accessed on 25 February 2021).

4. Taylor, S.; Landry, C.A.; Rachor, G.S.; Paluszek, M.M.; Asmundson, G.J.G. Fear and avoidance of healthcare workers: An important, under-recognized form of stigmatization during the COVID-19 pandemic. J. Anxiety Disord. 2020, 75. [CrossRef] [PubMed]

5. Ahmadi, H.; Ebrahimi, A.; Ghorbani, F. The impact of COVID-19 pandemic on dental practice in Iran: A questionnaire-based report. BMC Oral Health 2020, 20. [CrossRef] [PubMed]

6. Mahdee, A.F.; Gul, S.S.; Abdulkareem, A.A.; Qasim, S.S.B. Anxiety, practise modification, and economic impact among Iraqi dentists during the COVID-19 outbreak. Front. Med. 2020, 7. [CrossRef]

7. Ministry of Health of Slovak Republic. Available online: https://korona.gov.sk/wp-content/uploads/2020/04/Covid-19-Zubnelekarstvo.pdf (accessed on 4 January 2021).

8. Hoernke, K.; Djellouli, N.; Andrews, L.; Lewis-Jackson, S.; Manby, L.; Martin, S.; Vanderslott, S.; Vindrola-Padros, C. Frontline healthcare workers' experiences with personal protective equipment during the COVID-19 pandemic in the UK: A rapid qualitative appraisal. BMJ Open 2021, 11. [CrossRef]

9. Cohen, J.; Rodgers, Y.V.D.M. Contributing factors to personal protective equipment shortages during the COVID-19 pandemics. Prev. Med. 2020, 141. [CrossRef]

10. National Nurses United. Available online: https://www.nationalnursesunited.org/press/new-survey-results (accessed on 4 January 2021).

11. Ruengorn, C.; Awiphan, R.; Wongpakaran, N.; Wongpakaran, T.; Nochaiwong, S. Association of job loss, income loss, and financial burden with adverse mental health outcomes during coronavirus disease 2019 pandemic in Thailand: A nationwide cross-sectional study. Depress. Anxiety 2021, in press. [CrossRef]

12. Ali, S.; Maguire, S.; Marks, E.; Doyle, M.; Sheehy, C. Psychological impact of the COVID-19 pandemic on healthcare workers at acute hospital settings in the South-East of Ireland: An observational cohort multicentre study. BMJ Open 2020, 10. [CrossRef]

13. Chew, Q.H.; Wei, K.C.; Vasoo, S.; Sim, K. Psychological and coping responses of health care workers toward emerging infectious disease outbreaks: A rapid review and practical implication for the COVID-19 Pandemic. J. Clin. Psychiatry 2020, 81. [CrossRef] [PubMed] 
14. Celmece, N.; Menekay, M. The effect of Stress, Anxiety and Burnout Levels of Healthcare Professionals Caring for COVID19 Patients on Their Quality of Life. Front. Psychol. 2020, 11. [CrossRef]

15. Windarwati, H.D.; Ati, N.A.L.; Paraswati, M.D.; Ilmy, S.K.; Supianto, A.A.; Rizzal, A.F.; Sulaksono, A.D.; Lestari, R.; Supriati, L. Stressor, coping mechanism, and motivation among health care workers in dealing with stress due to the COVID-19 pandemic in Indonesia. Asian J. Psychiatry 2020, 56. [CrossRef]

16. Orrú, G.; Marzetti, F.; Conversano, C.; Vagheggini, G.; Miccoli, M.; Ciacchini, R.; Panait, E.; Gemignani, A. Secondary traumatic stress and burnout in healthcare workers during COVID-19 outbreak. Int. J. Environ. Res. Public Health 2021, 18, 1-13. [CrossRef]

17. Serrao, C.; Duarte, I.; Castro, L.; Teixeira, A. Burnout and depression in portuguese healthcare workers during the covid19 pandemic-The mediating role of psychological resilience. Int. J. Environ. Res. Public Health 2021, 18, 1-13. [CrossRef] [PubMed]

18. Sarapultseva, M.; Zolotareva, A.; Kritsky, I.; Nasretdinova, N.; Sarapultsev, A. Psychological distress and post-traumatic symptomology among dental healthcare workers in Russia: Results of a pilot study. Int. J. Environ. Res. Public Health 2021, 18. [CrossRef]

19. Chen, H.; Wang, B.; Cheng, Y.; Muhammad, B.; Li, S.; Miao, Z.; Wan, B.; Abdul, M.; Zhao, Z.; Geng, D.; et al. Prevalence of posttraumatic stress symptoms in health care workers after exposure to patients with COVID-19. Neurobiol. Stress 2020, 13. [CrossRef] [PubMed]

20. Toh, S.G.; Ang, E.; Devi, K.M. Systematic review on the relationship between the nursing shortage and job satisfaction, stress and burnout levels among nurses in oncology/haematology settings. Int. J. Evid. Based Health 2012, 10, 126-141. [CrossRef]

21. An, Y.; Yang, Y.; Wang, A.; Li, Y.; Zhang, Q.; Cheung, T.; Ungvari, G.S.; Qin, M.-Z.; An, F.-R.; Xiang, Y.-T. Prevalence of depression and its impact on quality of life among frontline nurses in emergency departments during the COVID-19 outbreak. J. Affect. Disord. 2020, 276, 312-315. [CrossRef] [PubMed]

22. Suryavanshi, N.; Kadam, A.; Dhumal, G.; Nimkar, S.; Mave, V.; Gupta, A.; Cox, S.R.; Gupte, N. Mental health and quality of life among healthcare professionals during the COVID-19 pandemic in India. Brain. Behav. 2020, 10. [CrossRef] [PubMed]

23. Buselli, R.; Corsi, M.; Baldanzi, S.; Chiumiento, M.; Lupo, E.D.; Dell 'Oste, V.; Bertelloni, C.A.; Massimetti, G.; Dell 'Osso, L.; Cristaudo, A.; et al. Professional Quality of Life and Mental Health Outcomes among Health Care Workers Exposed to Sars-Cov-2 (Covid-19). Int. J. Environ. Res. Public Health 2020, 17. [CrossRef]

24. Ungureanu, B.S.; Vladut, C.; Bende, F.; Sandru, V.; Tocia, C.; Turcu-Stiolica, R.-A.; Groza, A.; Balan, G.G.; Turcu-Stiolica, A. Impact of the COVID-19 Pandemic on Helath-Related Quality of Life, Anxiety, and Training among Young Gastroenterologists in Romania. Front. Psychol. 2020, 11. [CrossRef]

25. Dou, Z.; Stefanovski, D.; Galligan, D.; Lindem, M.; Rozin, P.; Chen, T.; Chao, A.M. Household food dynamics and food system resilience amid the COVID-19 pandemic: A cross-national comparison of China and the United States. Front. Sustain. Food Syst. 2021, 4. [CrossRef]

26. Yerkes, M.A.; André, S.C.H.; Besamusca, J.W.; Kruyen, P.M.; Remery, C.L.H.S.; Zwan, R.V.D.Z.; Beckers, D.G.J.; Geurts, S.A.E. 'Intelligent' lockdown, intelligent effects? Results from a survey on gender (in)equality in paid work, the division of childcare and household work, and quality of life among parents in the Netherlands during the Covid-19 lockdown. PLOS ONE 2020, 15. [CrossRef] [PubMed]

27. Boca, D.D.; Oggero, N.; Profeta, P.; Rossi, M. Women's and men's work, housework and childcare, before and during COVID-19. Rev. Econ. Househ. 2020, in press. [CrossRef]

28. Prime, H.; Wade, M.; Browne, D.T. Risk and resilience in family well-being during the COVID-19 pandemic. Am. Psychol. 2020, 75, 631-643. [CrossRef] [PubMed] 